\title{
Video-assisted thoracoscopic surgery for the treatment of lung cancer
}

\section{ABSTRACT}

A growing proportion of lung resections is being performed by video-assisted thoracoscopic surgery (VATS). VATS lobectomy is indicated for clinical stage I suspected lung cancer with pulmonary function sufficient to tolerate resection. Retrospective and matched analyses suggest less morbidity with fewer postoperative complications with VATS compared with open lobectomy. Five-year survival for VATS lobectomy in stage I non-small lung cancer patients approaches $80 \%$. A potential oncologic benefit of VATS lobectomy (over thoracotomy) has been proposed through attenuation of postoperative cytokine release. Regardless of whether VATS or an open approach is utilized, thorough lymphadenectomy is important and may confer an additional survival benefit.

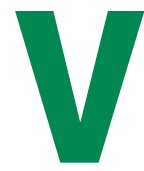

ideo-assisted thoracoscopic surgery (VATS) is emerging as a therapeutic option for a variety of thoracic applications. When applied to the patient with lung cancer, the therapeutic benefit of VATS lobectomy appears to be confined to node-negative, relatively small tumors. Operable patients with larger tumors are currently best served by thoracotomy and mediastinal lymph node dissection. As an alternative to thoracotomy for stage I lung cancer, VATS lobectomy is associated with less postoperative pain, less surgical morbidity, fewer complications, and shorter hospitalization. ${ }^{1-4}$

\section{LIMITED SPECIALIZED INSTRUMENTATION REQUIRED}

Technologic innovation in minimally invasive surgery applied to the lung has lagged behind that of radiation oncology and interventional cardiology.

Dr. Murthy reported that he has received royalties from Hood Laboratories.

This article was developed from an audio transcript of Dr. Murthy's presentation at the "Advances in Lung Cancer Evaluation and Management" symposium held in Cleveland, Ohio, on April 30, 2011. The transcript was formatted and edited by Cleveland Clinic Journal of Medicine staff for clarity and conciseness and was then reviewed, revised, and approved by Dr. Murthy. doi:10.3949/ccjm.79.s2.05
VATS lobectomy requires relatively limited specialized instrumentation beyond standard minimally invasive surgical instruments commonly used for a variety of nonthoracic operations.

Video-assisted thoracoscopic surgery takes advantage of the reproducible anatomy of the lungs. However, knowledge of the vascular and bronchial anatomy is essential to avoid compromise of critical structures during VATS lobectomy.

The indication for VATS lobectomy at Cleveland Clinic is suspected clinical stage I lung cancer with pulmonary function sufficient to tolerate resection. A peripheral cancer or nodule of $3 \mathrm{~cm}$ or less is preferable for minimally invasive thoracic surgery.

Until 2007, the definition of a VATS lobectomy lacked uniformity. A standardized definition of VATS was provided by the Cancer and Leukemia Group B, which conducted a prospective multiinstitutional feasibility study of VATS lobectomy. It defined a true VATS lobectomy as one with individual identification and ligation of lobar vessels and bronchus, with accompanying hilar and mediastinal lymph node sampling or dissection, and performed without rib spreading. ${ }^{5}$

\section{VATS OUTCOMES: FEWER COMPLICATIONS, SHORTER LENGTH OF STAY}

The proportion of lung resections by VATS has increased steadily in the United States over the past decade, reaching $29 \%$ in $2007 .{ }^{1}$ The obvious question is whether thoracoscopic lobectomy holds an advantage over thoracotomy in terms of morbidity. Park documented significantly less postoperative atrial fibrillation, blood transfusion, renal failure, and other complications when VATS lobectomy was compared with thoracotomy (Table). ${ }^{4}$

In a propensity-matched analysis, Paul et al ${ }^{1}$ found an overall lower rate of complications with VATS compared with open lobectomy $(26.2 \%$ vs $34.7 \%$; $P<.0001)$, including a lower incidence of arrhythmia $(7.3 \%$ vs $11.5 \% ; P=.0004)$, a lower frequency 
TABLE

Postoperative complications: thoracotomy versus video-assisted thoracic surgery (VATS)

\begin{tabular}{|c|c|c|c|}
\hline Complications & $\begin{array}{l}\text { Conventional } \\
\text { thoracotomy } \\
(\mathrm{n}=284) \\
\mathrm{n}(\%)\end{array}$ & $\begin{array}{l}\text { VATS } \\
(\mathrm{n}=284) \\
\mathrm{n}(\%)\end{array}$ & $P$ value \\
\hline Atrial fibrillation & $61(21)$ & $37(13)$ & .01 \\
\hline Atelectasis & $34(12)$ & $15(5)$ & .006 \\
\hline Prolonged air leak & $55(19)$ & $37(13)$ & .05 \\
\hline Transfusion & $36(13)$ & $11(4)$ & .002 \\
\hline Pneumonia & $27(10)$ & $14(5)$ & .05 \\
\hline Sepsis & $6(2)$ & $1(0.4)$ & .12 \\
\hline Renal failure & $15(5)$ & $4(1.4)$ & .02 \\
\hline $\begin{array}{l}\text { Chest tube duration, } \\
\text { median ( } 25 \text { th, } 75 \text { th } \\
\text { quartile), } d\end{array}$ & $4(3,6)$ & $3(2,4)$ & $.0001^{a}$ \\
\hline $\begin{array}{l}\text { Length of hospitalization, } \\
\text { median ( } 25 \text { th, } 75 \text { th } \\
\text { quartile), d }\end{array}$ & $5(4,7)$ & $4(3,6)$ & $.0001^{\mathrm{a}}$ \\
\hline Death & $15(5)$ & $8(3)$ & .20 \\
\hline No complications & $144(51)$ & $196(69)$ & .0001 \\
\hline \multicolumn{4}{|l|}{ aWilcoxon signed-rank test. } \\
\hline \multicolumn{4}{|c|}{$\begin{array}{l}\text { Adapted from The Journal of Thoracic and Cardiovascular Surgery (Villamizar } \\
\text { NR, et al. Thoracoscopic lobectomy is associated with lower morbidity compared } \\
\text { with thoracotomy. J Thor Cardiovasc Surg 2009; 138:419-425), copyright } \odot 2009 \text {, } \\
\text { with permission from The American Association for Thoracic Surgery. } \\
\text { www.sciencedirect.com/science/journal/00225223 }\end{array}$} \\
\hline
\end{tabular}

of blood transfusion $(2.4 \%$ vs $4.7 \% ; P=.0028)$, a reduced need for reintubation $(1.4 \%$ vs $3.1 \%$; $P=$ .0046 ), and a shorter length of stay (4.0 vs 6.0 days; $P<.0001)$ and chest tube duration (3.0 vs 4.0 days; $P<.0001)$. At Cleveland Clinic, length of hospital stay has been shortened by about 1 day in patients undergoing VATS compared with open lobectomy.

The advantage of thoracoscopic lobectomy compared with thoracotomy may be limited to reduction in associated morbidity alone. Five-year survival was $78 \%$ in a series of 411 patients with clinical stage I non-small cell lung cancer (NSCLC) who underwent VATS lobectomy and the more technically difficult VATS segmentectomy. ${ }^{6}$ This rate of survival is equivalent to or better than any other reported series of patients with stage I NSCLC.

A potential oncologic benefit to the VATS approach through preservation of host immunity has also been suggested. Release of inflammatory mediators such as interleukin (IL)-6, IL-8, and IL-10 has been observed following thoracotomy and a subse- quent immunosuppressive effect proposed. Liberation of these inflammatory cytokines appears attenuated by the VATS approach. Cellular proliferation and stimulation of tumor growth may be consequences of postoperative cytokine release, and limiting liberation of these products may have a direct beneficial tumor effect. ${ }^{?}$

\section{MEDIASTINAL LYMPHADENECTOMY}

Meticulous clinical staging of lung cancer directs clinical decision-making and has prognostic value. Imaging with computed tomography (CT) and fluorodeoxyglucose (FDG) positron emission tomography (PET) is neither sensitive nor specific for nodal metastases. The increasing popularity of less invasive staging and operative approaches for lung cancer imparts the risk of obtaining inadequate mediastinal information and the potential for undertreatment or overtreatment. At a minimum, systematic lymph node sampling is an essential component of any surgical approach (minimally invasive or open). Lymph node sampling should not be compromised by VATS, although more expertise is required for a complete VATS lymphadenectomy.

In patients with early-stage lung cancer, thorough lymphadenectomy may confer an important survival benefit even if sampled lymph nodes are found to be negative. ${ }^{8}$ Resection of occult (undetected) disease is one potential explanation for this survival benefit.

\section{CASE STUDY: LYMPHADENECTOMY VIA MINIMALLY INVASIVE TECHNIQUE}

A 45-year-old man with a 15 pack-year history of tobacco use presented with chest pain. He quit smoking 3 years previously. Although his chest pain resolved, a lesion in the right chest was incidentally found on chest radiograph.

The patient underwent spirometry and had normal values. A follow-up CT revealed a $2.1-\mathrm{cm}$ spiculated right upper lobe nodule. There was no significant nodule uptake of FDG (standardized uptake value: 1.5 to 1.8 ) on PET. Percutaneous fine-needle aspiration biopsy demonstrated atypical cells of unclear significance. Navigational bronchoscopy-directed biopsy also revealed atypical cells but was nondiagnostic. The concern was that because the size of the mass was $2.1 \mathrm{~cm}$, surveillance was not a viable option.

Ultimately, because of the biopsy ambiguity, large nodule size, and excellent patient performance status, VATS resection was offered. As a prelude, the mediastinum was staged with mediastinoscopy. The entire central (N2) compartment was surveyed with 
this technique and all samples were found to be free of cancer.

A VATS lobectomy was then performed. One utility incision $(4 \mathrm{~cm})$ was made and two to three ports $(1 \mathrm{~cm}$ each) were placed within the thorax. No ribspreading was utilized. An anatomic lobectomy with division of major vascular structures and the bronchus was performed similarly to an open procedure. When fully mobilized, the specimen (the right upper lobe in this case) was placed in a protective bag and delivered through the utility incision. Regional lymph nodes were also harvested for pathologic examination.

This patient was found to have a T1aNOMO NSCLC and had an uneventful 3-day hospital course. Based on this final pathology and on institutional data, his projected survival was approximately $85 \%$, $10 \%$ to $15 \%$ higher than national averages. ${ }^{8}$

\section{SUMMARY}

VATS lung resection is slowly becoming the standard of care for patients with stage I lung cancer. Advantages to the VATS approach compared with open lobectomy are less morbidity and shorter hospitalization. The perioperative stress response is attenuated with VATS, which suggests a potential superior oncologic outcome, although this remains to be proved. A complete mediastinal lymphadenectomy, regardless of the approach, may confer a survival advantage in early-stage lung cancer.

\section{REFERENCES}

1. Paul S, Altorki NK, Sheng S, et al. Thoracoscopic lobectomy is associated with lower morbidity than open lobectomy: a propensitymatched analysis from the STS database. J Thorac Cardiovasc Surg 2010; 139:366-378.

2. Villamizar NR, Darrabie MD, Burfeind WR, et al. Thoracoscopic lobectomy is associated with lower morbidity compared with thoracotomy. J Thorac Cardiovasc Surg 2009; 138:419-425.

3. Swanson SJ, Meyers BF, Gunnarsson CL, et al. Video-assisted thoracoscopic surgical lobectomy is less costly and morbid than open lobectomy: a retrospective multiinstitutional database analysis [published online ahead of print November 28, 2011]. Ann Thorac Surg. doi:10.1016/j.athoracsur.2011.06.007.

4. Park BJ. Is surgical morbidity decreased with minimally invasive lobectomy? Cancer J 2011; 17:18-22.

5. Swanson SJ, Herndon II JE, D'Amico TA, et al. Video-assisted thoracic surgery lobectomy: report of CALGB 39802 - a prospective, multi-institution feasibility study. J Clin Oncol 2007; 25:4993-4997.

6. Nakamura H, Taniguchi $\mathrm{Y}$, Miwa $\mathrm{K}$, et al. Comparison of the surgical outcomes of thoracoscopic lobectomy, segmentectomy, and wedge resection for clinical stage I non-small cell lung cancer. Thorac Cardiov Surg 2011; 59:137-141.

7. Whitson BA, D'Cunha J. Video-assisted thoracoscopic surgical lobectomy: the potential oncological benefit of surgical immunomodulation. Semin Thorac Cardiovasc Surg 2010; 22: $113-115$.

8. Murthy SC, Reznik SI, Ogwudu UC, et al. Winning the battle, losing the war: the noncurative "curative" resection for stage I adenocarcinoma of the lung. Ann Thorac Surg 2010; 90; $1067-1074$

Correspondence: Sudish Murthy, MD, PhD, Department of Thoracic and Cardiovascular Surgery, Cleveland Clinic, 9500 Euclid Avenue, J4-1, Cleveland, OH 44195; MURTHYS1@ccf.org 